\title{
Aspiration and altered airway anatomy: a presentation with a twist
}

\author{
Sarah Cullivan, ${ }^{1}$ Thomas Langø, ${ }^{2}$ Padraig Cantillon-Murphy, ${ }^{3}$ Marcus P Kennedy ${ }^{1}$
}

'Department of Respiratory Medicine, Cork University Hospital, Cork, Ireland ${ }^{2}$ Department of Health, SINTEF and Research Division, St. Olavs Hospital, Norway, Norway ${ }^{3}$ Department of Electronic Engineering, University College Cork, Cork, Ireland

\section{Correspondence to} Dr Sarah Cullivan, sarah.cullivan@ucdconnect.ie

Accepted 8 May 2018

\section{DESCRIPTION}

A 60-year-old woman presented to our hospital with severe hypercapnic respiratory failure in the absence of a prior smoking history. She reported a 1-day history of increased dyspnoea and a cough productive of green sputum. Her medical history was significant for severe idiopathic scoliosis, cleft palate repair, rheumatoid arthritis, hypothyroidism and recurrent lower respiratory tract infections. She was obtunded on presentation and required 24 hours of mechanical ventilation.

A CT thorax was performed to further investigate her acute deterioration. Considerable distortion of thoracic anatomy secondary to kyphoscoliosis was noted. Right lower lobe atelectasis due to extrinsic compression of the bronchus intermedius by thoracic vertebrae and left lower lobe consolidation were reported (figures 1-3). Due to the vertical orientation of the left main bronchus (LMB), aspiration pneumonia was suspected (figure 2). Our patient initially improved with antimicrobial therapy, dietary modifications and proton pump inhibitors and was discharged home.

Unfortunately, she represented to our centre on two occasions in the proceeding months with recurrent hypercapnic respiratory failure, requiring mechanical ventilation. A bronchoscopy, performed on the second admission, excluded foreign body aspiration and microbiological samples isolated Klebsiella oxytoca (an organism associated with aspiration pneumonia), which will alter future

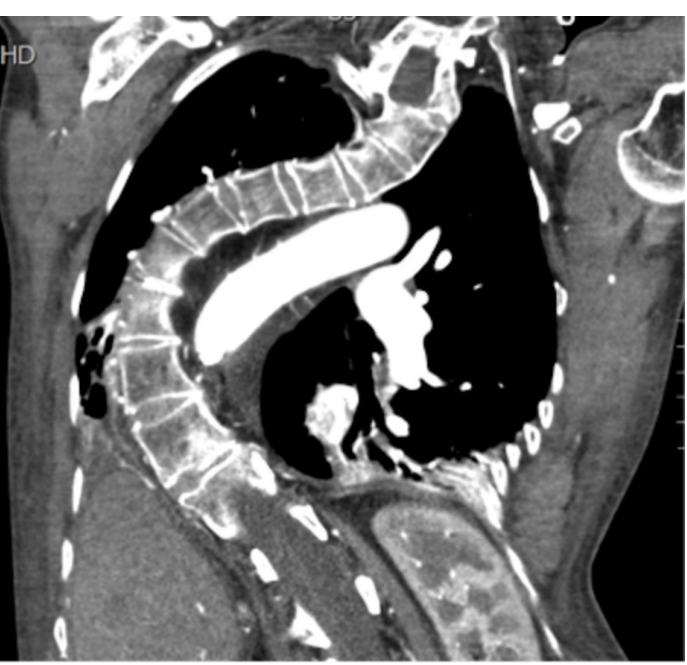

Figure 1 Sixty-year-old woman with aspiration pneumonia and hypercapnic respiratory failure. Coronal cross-section $\mathrm{CT}$ with contrast demonstrates severe scoliosis (Cobb angle $>70^{\circ}$ ).

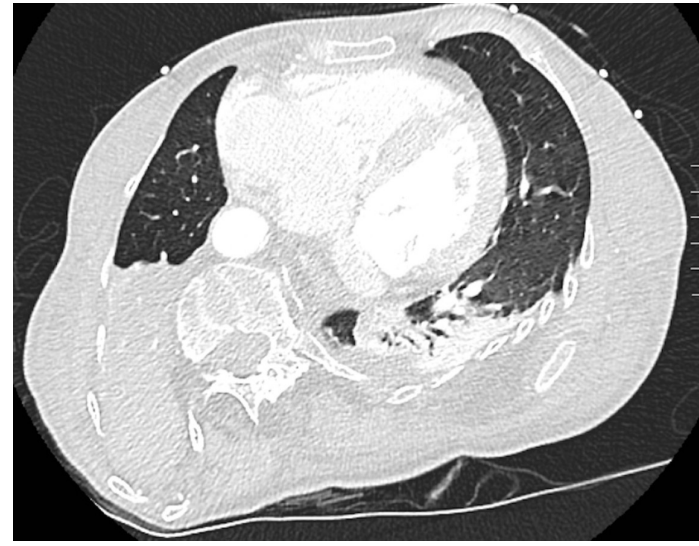

Figure 2 Sixty-year-old woman with aspiration pneumonia and hypercapnic respiratory failure. Axial CT of the chest demonstrates left lower lobe pneumonia.

antimicrobial choice. Recurrent aspiration pneumonia and progressive respiratory failure due to restrictive lung disease were diagnosed. Subsequent multidisciplinary assessment including high resolution oesophageal motility study and endoscopy revealed evidence of asymptomatic aspiration due to oesophagogastric junction outflow obstruction. Our patient was educated regarding compliance with dietary modifications and later discharged to convalescence. She will be followed in outpatients, with a view to repeat endsocopy with oesophageal dilation and assessment for nocturnal non-invasive positive pressure ventilation (NIPPV).

This case highlights important concepts regarding airway anatomy and progressive respiratory failure in cases of severe scoliosis. Scoliosis results in extrapulmonary restriction, displaces intrathoracic organs and significantly alters respiratory mechanics. Furthermore, mechanical airflow obstruction and chronic atelectasis may occur due to airway compression by thoracic vertebrae. This confers a biomechanical disadvantage, and these patients are at risk of chronic respiratory failure. ${ }^{12}$

Regarding airway anatomy, typically, the trachea is centred in the midline and the right main bronchus (RMB) branches at $25^{\circ}-30^{\circ}$, while the LMB branches at a greater angle of approximately $45^{\circ}$ from the midline. ${ }^{1}$ Consequently, the lesser angle of the RMB classically predisposes the right lung to aspiration injury. Interestingly in this case, the trachea is deviated to the left of the midline and the LMB has a vertical orientation, predisposing the left lung to aspiration pneumonia (figure 3 ).

This is an interesting case of acute-on-chronic respiratory failure. Acute respiratory failure 


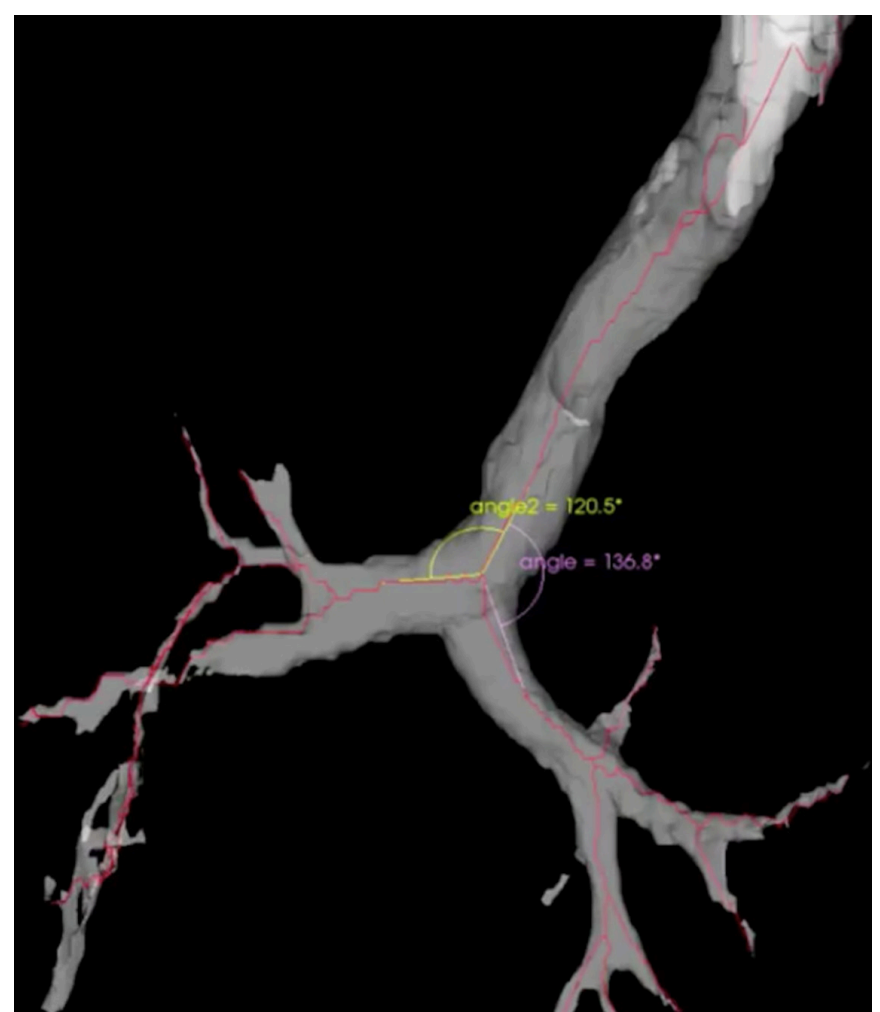

Figure 3 Three-dimensional reconstruction of external airway anatomy in a patient with scoliosis and altered airway anatomy. In this reconstructed image, left lateral displacement of the trachea due to scoliosis can be seen. Focal stenosis of the bronchus intermedius is noted due to extrinsic compression by thoracic vertebrae. Additionally, the vertical orientation of the left lower lobe bronchus is demonstrated. The image was generated using the open source software Fraxinus (www.custusx.org/fraxinus), a tool for planning bronchoscopy.

occurred in the context of recurrent aspiration of multifactorial pathogenesis. Dietary modifications were introduced to address dysphagia, and repeat endoscopy with oesophageal dilation is planned. Chronic respiratory failure due to established severe idiopathic scoliosis was more challenging to address. While surgery and bracing can alleviate deformity and restore anatomy, our patient elected not to pursue these options. Therefore, assessment for nocturnal NIPPV was organised, as this can alleviate respiratory symptoms associated with ventilatory failure, addresses nocturnal hypoventilation and reduce hospitalisations for respiratory illnesses. ${ }^{3}$

\section{Learning points}

- Aspiration should always be considered in cases of recurrent acute respiratory failure and pneumonia, even when overt symptoms of aspiration are absent.

- Typically, the right lung is susceptible to aspiration injury due to its more vertical orientation. However, in severe scoliosis, altered airway anatomy can predispose the left lung to aspiration.

- In cases of severe scoliosis, extrapulmonary restriction confers a biomechanical disadvantage that predisposes to chronic respiratory failure.

Contributors SC and MPK wrote this manuscript and were involved in the patient's care. TL and PC-M designed the 3D reconstruction represented in figure 3 . All authors have evaluated the case in detail and have approved the submission of the final manuscript.

Funding The authors have not declared a specific grant for this research from any funding agency in the public, commercial or not-for-profit sectors.

Competing interests None declared.

Patient consent Obtained.

Provenance and peer review Not commissioned; externally peer reviewed.

(C) BMJ Publishing Group Ltd (unless otherwise stated in the text of the article) 2018. All rights reserved. No commercial use is permitted unless otherwise expressly granted.

\section{REFERENCES}

1 Gorden JA. Relevant thoracic anatomy. Endobronchial ultrasound, an atlas and practical guide. Germany: Springer:13-25.

2 Koumbourlis AC. Scoliosis and the respiratory system. Paediatr Respir Rev 2006;7:152-60

3 Turkington PM, Elliott MW. Rationale for the use of non-invasive ventilation in chronic ventilatory failure. Thorax 2000;55:417-23.

Copyright 2018 BMJ Publishing Group. All rights reserved. For permission to reuse any of this content visit

http://group.bmj.com/group/rights-licensing/permissions.

BMJ Case Report Fellows may re-use this article for personal use and teaching without any further permission.

Become a Fellow of BMJ Case Reports today and you can:

- Submit as many cases as you like

- Enjoy fast sympathetic peer review and rapid publication of accepted articles

- Access all the published articles

- Re-use any of the published material for personal use and teaching without further permission

For information on Institutional Fellowships contact consortiasales@bmjgroup.com

Visit casereports.bmj.com for more articles like this and to become a Fellow 